\section{Abdominal aortic aneurysm repair in a patient with a cardiac transplant}

Annette MacIntyre MD FRCPC, Lawrie Garnett MD FRCPC
We describe successful elective abdominal aneurysm repair in a patient with a cardiac transplant. In light of the unique physiology and pharmacology of the denervated heart, this presented an unusual combination of complex problems. Whereas the normally innervated heart increases cardiac output via neural stimuli, the denervated heart relies primarily on the Frank Starling mechanism which is dependent on preload and myocardial contractility. Thus, rapidly changing haemodynamic variables associated with aortic cross-clamping require scrupulous attention to the maintenance of adequate preload as well as myocardial function which can only be manipulated by direct-acting agents. We conclude that the denervated heart will readily compensate for the haemodynamic changes brought about by infrarenal aortic crossclamping if a high-normal preload is maintained and if the transplanted donor heart is free of pathology with good inherent myocardial contractility.

On décrit le succès obtenu lors d'une réparation élective d'anévrisme abdominal d' un patient ayant subi une transplantation cardiaque. A cause de la physiologie et de la pharmacologie particulière du coeur dénervé, ceci a présenté une combination habituel de problèmes complexes. Alors qu' un coeur normalement innervé augmente le débit cardiaque à travers une stimulation nerveuse, le coeur dénervé dépend essentillement du mécanisme de Frank Starling qui est dépendant sur la précharge et la contractilité myocardique. Ainsi, les changements hémodynamiques rapides associés au clampage aortique requièrent une attention particulière pour le maintien d'une précharge

\section{Key words}

ANAESTHESIA: vascular;

ANAESTHETIC TECHNIQUES: general;

HEART: transplantation;

SURGERY: vascular.

From The Department of Anaesthesia, Ottawa Civic Hospital and the University of Ottawa, Ottawa, Ontario.

Address correspondence to: Dr. Annette MacIntyre, Department of Anaesthesia, Ottawa Civic Hospital, C-3; 1053

Carling Avenue, Ottawa, Ontario, K1Y 4E9.

Accepted for publication 6th May, 1991. adéquate ainsi qu'une fonction myocardique qui pourrait être manipulé uniquement par des agents à action directe. On conclut que le coeur dénervé compensera adéquatement lors des altérations hémodynamiques amenées par clampage aortique infrarenal si la précharge élevée à normale est maintenue et si le coeur du donneur transplanté est libre de toute pathologie, et présentant aussi une bonne contractilité myocardique.

Orthotopic cardiac transplantation has become standard therapy for idiopathic dilated cardiomyopathy and endstage coronary artery disease. As the number of patients undergoing cardiac transplantation increases and as survival improves, anaesthetists are more likely to encounter these patients as candidates for non-cardiac surgery. This is particularly true because the overall incidence of general surgical problems in cardiac transplant patients is approximately ten times higher than in patients without cardiac transplants. ${ }^{1}$ Patients with a cardiac transplant who require abdominal aortic aneurysm repair present the anaesthetist with an unusual combination of complex problems. Not only does the anaesthetic management need to consider the implications of abdominal aortic surgery, such as acute blood loss, large volume shifts and rapid changes in preload and afterload associated with aortic cross-clamping, but it also has to see these events in the light of the unique physiology and pharmacology of the transplanted and permanently denervated heart.

In the following report we describe the management of a patient with a cardiac transplant who presented for elective abdominal aortic aneurysm repair. Although general anaesthetic considerations for patients with a cardiac transplant have recently been reviewed, ${ }^{2}$ we are unaware of a previous report specifically describing elective abdominal aortic aneurysm repair in a cardiac transplant patient.

\section{Case report}

A 57-yr-old Caucasian man (height, $180 \mathrm{~cm}$; weight, 79 $\mathrm{kg}$ ) presented for resection of an asymptomatic abdominal aortic aneurysm which was diagnosed incidentally on ultrasound examination. It was confirmed by computer- 
TABLE Perioperative haemodynamic variables

\begin{tabular}{|c|c|c|c|c|c|c|}
\hline Event & $B p(m m H g)$ & $H R(b p m)$ & $C V P(m m H g)$ & $P C W P(\mathrm{mmHg})$ & $C l\left(L \cdot \min ^{-1} \cdot m^{-2}\right)$ & SVR $\left(\right.$ dyne $\left.\cdot \mathrm{s}^{-1} \cdot \mathrm{cm}^{-5}\right)$ \\
\hline Preoperative & $113 / 40$ & 72 & & & & \\
\hline \multicolumn{7}{|l|}{ Operation } \\
\hline Arrival in OR & $110 / ?$ & 98 & & & & \\
\hline Intubation & $115 / ?$ & 100 & & & & \\
\hline Pre-incision & $110 / 60$ & 93 & 7 & 11 & 3.5 & 858 \\
\hline 5 min post-incision & $132 / ?$ & 105 & & & & \\
\hline Bowel manipulation & $120 / 64$ & 110 & 8 & 13 & 4.4 & 671 \\
\hline 5 min pre-clamp on & $132 / 75$ & 98 & 9 & 14 & 4.3 & 828 \\
\hline $5 \mathrm{~min}$ post-clamp on & $138 / 81$ & 98 & 10 & 15 & 4.5 & 899 \\
\hline 5 min pre-clamp off & $165 / 90$ & 98 & 8 & 12 & 4.0 & 1185 \\
\hline $5 \mathrm{~min}$ post-clamp off & $150 / 84$ & 98 & 9 & 12 & 4.5 & 899 \\
\hline Departure from OR & $120 / ?$ & 88 & & 16 & & \\
\hline ICU arrival & $145 / 85$ & 85 & 10 & 10 & 3.8 & 877 \\
\hline
\end{tabular}

ized tomography to be infrarenal in origin, ending above the aortic bifurcation and measuring $6.5 \mathrm{~cm}$ in maximum transverse diameter. Two and a half years before presentation, the patient underwent an urgent cardiac transplantation after a massive myocardial infarction resulted in life-threatening cardiogenic shock. Since his transplant, the patient had been well and active. His symptoms before admission were mild shortness of breath on exertion, nocturia and frequent oesophageal reflux. He had no cardiac symptoms. He was being treated for hypertension with nifedipine $40 \mathrm{mg}$ po bid. His only other preoperative medications were deltacortisone $10 \mathrm{mg}$ po OD and cyclosporine $300 \mathrm{mg}$ po bid for immunosuppression. The physical examination was unremarkable except for a midline sternotomy scar. His blood pressure was $120 / 80$ $\mathrm{mmHg}$ and his heart rate was $100 \mathrm{bpm}$ and regular. An upper GI series and abdominal ultrasound examination revealed a hiatal hernia, gallstones and a right renal cyst. Preoperative cardiac angiography showed a normal left ventricle and normal coronary vessels. There were no signs of rejection on preoperative endomyocardial biopsy. Intra-cardiac pressures measured during the biopsy were normal. The preoperative ECG showed a normal sinus rhythm of $98 \mathrm{bpm}$ with occasional recipient $\mathrm{P}$ waves. There were no abnormalities on the preoperative chest $x$-ray. Pre-operative blood work was normal except for an elevated creatinine of $172 \mu \mathrm{mol} \cdot \mathrm{L}^{-1}$ (normal 65125) which was attributed to cyclosporine. The preoperative plasma cyclosporine concentration was $208 \mathrm{mg} \cdot \mathrm{L}^{-1}$ (normal 150-400). The preoperative haemoglobin concentration was $122 \mathrm{~g} \cdot \mathrm{L}^{-1}$.

In summary, this 57-yr-old man with a cardiac transplant presented for elective abdominal aortic aneurysm resection. He had controlled hypertension, iatrogenic adrenocorticosuppression and immunosuppression, renal insufficiency, a symptomatic hiatal hernia and asymptomatic gallstones.

The patient received ranitidine $150 \mathrm{mg}$ po and diazepam $10 \mathrm{mg}$ po for premedication. Perioperative steroid coverage was maintained with hydrocortisone, $100 \mathrm{mg} i v$ on call to the operating room, followed by $50 \mathrm{mg} i \mathrm{v}$ every eight hours. Perioperative immunosuppression commenced with cyclosporine $300 \mathrm{mg}$ po before surgery followed by a continuous cyclosporine infusion, starting at $2.8 \mathrm{mg} \cdot \mathrm{hr}^{-1}$ and titrated to daily cyclosporine levels. In addition to the routine monitors, a pulmonary artery catheter was inserted via the right internal jugular vein. An arterial line was inserted in the left radial artery. A strict aseptic technique was observed during line placement. Continuous ST-segment analysis was used in leads $\mathrm{V}_{5}$ and II with a Siemens Monitor Model 1281. Anaesthesia was induced with iv fentanyl $(1500 \mu \mathrm{g})$ and iv midazolam (5 mg). Muscle relaxation was achieved with pancuronium (10 mg). Cricoid pressure was applied until the trachea was intubated. Anaesthesia was maintained with increments of $i v$ fentanyl (total intraoperative dose: $3500 \mu \mathrm{g}$ ) and isoflurane $0.25-1.5 \%$ with $50 \%$ oxygen in air, titrated to maintain blood pressure within $20 \%$ of preoperative values. A nitroglycerine infusion (0.25-1 $\mu \mathrm{g} \cdot \mathrm{kg}^{-1} \cdot \min ^{-1}$ ) was used for further blood pressure control and to allow volume loading once the aorta was clamped. Dopamine $\left(2 \mu \mathrm{g} \cdot \mathrm{kg}^{-1} \cdot \mathrm{min}^{-1} i v\right)$ was started approximately $15 \mathrm{~min}$ before aortic cross-clamping and continued into the postoperative period to improve renal blood flow.

Perioperative haemodynamic variables are shown in the Table. During bowel manipulation the patient's face became obviously flushed. Systemic vascular resistance decreased along with a lesser decrease in mean arterial pressure. The heart rate increased slightly. This was a 
continuation of a gradual increase in heart rate which started before the bowel manipulation. It was not directly related to the decrease in systemic vascular resistance during bowel manipulation. The heart rate was lowered with $1 \mathrm{mg}$ increments of $i v$ metroprolol up to a total of 4 mg. No ST-segment changes were noted intraoperatively. The duration of surgery was six hours and aortic crossclamp time was $100 \mathrm{~min}$. Intraoperative blood loss was estimated at $1300 \mathrm{ml}$. The patient received $500 \mathrm{ml}$ of autologous blood collected intraoperatively, $5000 \mathrm{ml}$ of crystalloid and $200 \mathrm{ml}$ of $25 \%$ albumin. Total intraoperative urine output was $600 \mathrm{ml}$.

After surgery the patient was taken to the Intensive Care Unit (ICU) where the lungs were ventilated overnight. The trachea was easily extubated the next morning. The dopamine and nitroglycerine infusions were stopped shortly after arrival in the ICU. There were no changes on postoperative serial 12-lead ECG's. The postoperative haemoglobin concentration was $9.7 \mathrm{~g} \cdot \mathrm{L}^{-1}$ and creatinine concentration was $115 \mu \mathrm{mol} \cdot \mathrm{L}^{-1}$. After extubation on the first postoperative day, the chest $x$-ray showed minimal interstitial oedema. At the time, the patient's pulmonary capillary wedge pressure was $18 \mathrm{mmHg}$ and his cardiac output was $7.9 \mathrm{~L} \cdot \mathrm{min}^{-1}$. Thus the chest $x$-ray findings were attributed to a mild volume overload rather than myocardial failure. The lungs were clear by the second postoperative day when the patient was discharged from the ICU. He recovered uneventfully except for a mild urinary tract infection which was treated with oral antibiotics. He left the hospital on the tenth postoperative day.

\section{Discussion}

The anaesthetic considerations for patients with cardiac transplants should begin with a review of the alterations in cardiac physiology and pharmacology resulting from denervation. Once the human heart has been denervated, it is unlikely to undergo reinnervation. ${ }^{2}$ Because of the lack of vagal tone, the resting heart rate of the denervated heart is usually between $95-105 \mathrm{bpm} .{ }^{3}$ As a direct result of cardiac denervation, all autonomic reflex mechanisms of the heart are abolished. ${ }^{2}$

In the innervated heart, increased cardiac output in response to stress or exercise is achieved via neural stimuli which lead primarily to an increase in heart rate, followed almost simultaneously by an increase in the contractile force of the myocardium. ${ }^{4}$ Although the exact mechanism is unclear, the denervated heart increases cardiac output mainly by increasing preload and thus left ventricular end-diastolic volume. This mediates an increase in stroke volume and ejection fraction by means of the Frank-Starling mechanisms. ${ }^{5}$ Increased cardiac output is then maintained by a heart rate which slowly increases over five to six minutes in response to increasing concentrations of circulating catecholamines which directly stimulate the sinus node..$^{2,4-6}$

The effects of vasoactive drugs or anaesthetic agents on the denervated heart depend on whether the drug's action is primarily direct or indirect. ${ }^{2}$ Direct acting agents such as isoproterenol, epinephrine or norepinephrine continue to act predictably. ${ }^{7}$ However, the usual accompanying autonomic reflex changes in heart rate, such as bradycardia in response to neosynephrine, may be absent. Some patients may exhibit denervation hypersensitivity, resulting in an exaggerated response to direct-acting drugs, e.g., $\beta$-agonists. ${ }^{8}$ Indirect agents (e.g., atropine, glycopyrrolate, pancuronium) have no effect on heart rate, since they act only via neural pathways. ${ }^{7}$ Mixed agents such as ephedrine and dopamine will have similar effects as on innervated hearts. ${ }^{9}$

Transplanted hearts are susceptible to accelerated atherosclerosis. This occurs in approximately $30-35 \%$ of cardiac transplant patients within three years of transplantation. ${ }^{10}$ Because of cardiac denervation, heart transplant patients do not develop angina. It is thus highly desirable to have a preoperative cardiac angiogram for objective assessment of the left ventricle and coronary vessels. Preoperative cardiac biopsy will show any evidence of graft rejection. It is vital to rule out graft rejection since this is a primary cause of cardiac dysfunction and failure which could lead to catastrophe during aortic aneurysm repair. Cardiac transplant patients have regular cardiac angiograms and endomyocardial biopsies as part of their routine follow-up. Every effort should be made to communicate with the patient's cardiologist before surgery in order to obtain the results of the latest examinations. Most patients (75\%) with a cardiac transplant who are not rejecting are New York Heart Association functional class 1. ${ }^{11}$ Cardiac dysrhythmias are common in recently transplanted hearts but the incidence decreases in long-term survivors. ${ }^{12}$ There were no perioperative dysrhythmias in our patient.

All patients with heart transplants receive immunosuppression. In our patient, this was achieved with cyclosporine and deltacortisone. Our patient presented with several manifestations of their side-effects which have been reviewed previously. ${ }^{2}$ The hypertension, renal insufficiency, oesophagitis and cholelithiasis were all attributed to the immunosuppressive regimen. Strict attention to asepsis is crucial in these immunosuppressed patients and "stress" steroid coverage is usually required.

The anaesthetic goals for our patient were primarily based on what is known about denervated heart physiology and pharmacology and the anticipated needs for control of haemodynamic variables in the face of aortic cross-clamping and the possibility of acute blood loss. 
Because the denervated heart relies primarily on the Frank Starling mechanism to increase cardiac output, our foremost concern was to maintain adequate preload by avoiding hypovolaemia. A pulmonary artery catheter was used, despite the increased risk of sepsis, because accurate measurement of volume status was crucial for the maintenance of haemodynamic stability.

Myocardial depression was minimized by choosing a narcotic-based anaesthetic technique with small increments of isoflurane. Narcotics do not have a vagotonic effect on the denervated heart. Isoflurane, as a main anaesthetic agent in high doses, could have exaggerated hypotension due to the absence of a reflex heart rate increase in response to vasodilation. ${ }^{2}$ This was not a problem with low-dose isoflurane supplementing narcoticbased anaesthesia. Nitrous oxide was not used because of its potential in causing hypotension via direct myocardial depression which would not be offset by its sympathetic stimulating properties. ${ }^{13}$

An isoproterenol infusion was available throughout the intraoperative period in order to increase heart rate if this should have become necessary during a hypotensive episode. A direct acting $\beta$-agonist, like isoproterenol, is essential for the treatment of hypotension when stroke volume is adequate and systemic vascular resistance is normal. ${ }^{9}$ Alternatively, a pulmonary artery catheter with a pacing port may be used to increase heart rate. Tachycardia was treated with increments of $i v$ metoprolol, a selective $\beta$-antagonist, which opposes the direct effects of circulating catecholamines, released as part of the surgical stress response. Additional narcotics did not decrease the tachycardia probably because of their inability to affect heart rate via vagal mechanisms. ${ }^{2}$

The most important factor influencing the haemodynamic response of normally innervated hearts to aortic cross-clamping is the level of cross-clamping. Infra-renal cross-clamping only limits flow to the lower extremities and consequently produces only minor changes in blood pressure, systemic vascular resistance and stroke volume. ${ }^{14}$ The primary mechanism of compensation of the normally innervated heart to aortic cross-clamping is the Frank-Starling mechanism of increased contractility in face of an abruptly increased afterload. ${ }^{15,16}$ Denervation does not affect this compensatory mechanism. Compensation by the denervated heart to aortic cross-clamping depends entirely on the amount of contractile reserve of the myocardium and the degree of afterload for which it has to compensate. Since the donor heart of our patient was free of pathology and since cross-clamping at the infrarenal level produced only a small increase in afterload, it was not surprising that our patient showed little haemodynamic difference from patients with normally innervated hearts. We speculate that the response to aortic cross-clamping may result in less haemodynamic stability if the donor heart is diseased or if the cross-clamp level is above the renal arteries. This re-emphasizes the importance of determining the functional capacity of the donor heart preoperatively.

The cardiac index of our patient remained generally high-normal which was probably a direct reflection of the degree of unopposed contractile reserve of the donor heart. Systemic vascular resistance was low-normal which could have been a compensatory response to a cardiac index higher than necessary to maintain an adequate blood pressure. The haemodynamic response to bowel manipulation was most likely due to the release of vasoactive substances such as prostaglandins which is a frequently observed but not yet fully understood phenomenon. ${ }^{15}$ As was to be expected, the increase in heart rate in response to the decrease in systemic vascular resistance was insignificant. Blood pressure was easily restored with volume loading.

In summary, we have presented a patient with a cardiac transplant who successfully underwent elective abdominal aortic aneurysm repair. Intraoperative management was focussed primarily on the maintenance of a highnormal preload, avoidance of myocardial depression and control of heart rate with direct acting agents. If the denervated donor heart is strong and free of pathology, it will easily compensate for the haemodynamic changes brought about by infrarenal aortic crossclamping.

\section{Acknowledgements}

The authors wish to thank Drs. E. Wynands and G. Allen for reviewing the manuscript. We are grateful to Ms. Wilma Erickson for her secretarial assistance.

\section{References}

1 Merrell SA, Ames SA, Nelson EW et al. Major abdominal complications following cardiac transplantation. Arch Surg 1989; 124: 889-94.

2 Bailey $P L$, Stanley $T H$. Anesthesia for patients with a prior cardiac transplant. Journal of Cardiothoracic Anesthesia 1990; 4: 538-47.

3 Kent KM, Cooper $T$. The denervated heart: a model for studying autonomic control of the heart. $\mathrm{N}$ Engl $\mathrm{J}$ Med 1974; 291: 1017-21.

4 Pope SE, Stinson EB, Daughters GT et al. Exercise response of the denervated heart in long-term cardiac transplant recipients. Am J Cardiol 1980; 46: 213-8.

5 Brecker $S R W$, Sugden JC. Anaesthesia for surgery in a patient with a transplanted heart. Br J Anaesth 1985; 57 : 634-7.

6 Eisenkraft JB, Dimich I, Sachdev VP. Anesthesia for major noncardiac surgery in a patient with a transplanted heart. Mt Sinai J Med 1981; 48: 116-20. 
7 Mason JW, Harrison DC. Electrophysiology and electropharmacology of the transplanted human heart. In: Navula O (Ed.). Cardiac Arrhythmias: Electrophysiology, Diagnosis and Management, Baltimore: Williams and Wilkins, 1979; 66-81.

8 Jusef S, Phil D, Theodoropoulas $S$ et al. Increased sensitivity of the transplanted human heart to isoprenaline both before and after $\beta$-adrenergic blockade. Circulation 1987; 75: 696-704.

9 Kanter SF, Samuels SI. Anesthesia for major operations on patients who have transplanted hearts; a review of 29 cases. Anesthesiology 1977; 46: 65-8.

10 Renbund DG, Bristow MR, Lee HR, O'Connell JB. Medical aspects of cardiac transplantation. Journal of Cardiothoracic Anesthesia 1988; 2: 500-12.

11 Key TC, Resnik R, Dittrich HC, Reisner LS. Successful pregnancy after cardiac transplantation. Am J Obstet Gynecol 1989; 160: 367-71.

12 Schroeder JS, Berke DK, Graham AF. Arrhythmias after cardiac transplantation. Am J Cardiol 1974; 33: 604-7.

13 Ebert TJ, Kampine JP. Nitrous oxide augments sympathetic outflow: direct evidence from human peroneal nerve recordings. Anesth Analg 1989; 69: 444-9.

14 Roizen MF, Beaupre PN, Albert RA et al. Monitoring with two-dimensional transesophageal echocardiography. Comparison of myocardial function in patients undergoing supraceliac, suprarenal-infraceliac or infrarenal aortic occlusion. J Vasc Surg 1984; 1: 300-5.

15 Cunningham $A J$. Anaesthesia for abdominal aortic surgery - Part 1. Can J Anaesth 1989; 36: 426-44.

16 Lampe GH, Mangano DT. Anesthetic management for abdominal aortic reconstruction. In: Roizen MF (Ed.). Anesthesia for Vascular Surgery, New York: Churchill Livingstone Inc., 1990; 265-84. 